
work groups. The value of empathy can be observed in the nursing sector, where Kleiner and Wallace (2017) found a positive relationship between the degree of empathy and compassion exhibited by a nurse, and a patient's response to treatment and recovery time. This relationship, however, is not exclusive to the nursing sector, and is found in many other service-based sectors where caring or helping is a key focus (Mehrabin \& Epstein, 1972).

\title{
KEEPING IT REAL IN CHANGING TIMES: PRAGMATIC STRATEGIES TO SUSTAIN EMPATHY
}

\section{Marjolein Schaddelee, Samuel Turner and Lesley Gil}

\section{INTRODUCTION}

Empathy is still a frequently disputed component when it comes to leadership and in particular in relation to being able to take decisive action in times of change (Marques, 2015). After a mass shooting in two mosques in Christchurch in 2019, New Zealand's Prime Minister Jacinda Adern received international praise for her empathic leadership combined with the ability to take concrete actions related to gun control (Salam, 2019). Our research interest was initially sparked by findings in earlier research related to emotional intelligence (EI), which pointed to the value of the role of empathy for workers at all levels, and therefore the value of empathy training and development in the workplace. To follow up, interviews were undertaken in early 2017 with a mix of empathy trainers and managers of organisations where empathy is signalled as a key skill. The purpose of the inquiry was to mine their perspectives of empathy training and discover emerging themes of empathy in the workplace, identify relevant components that contribute to developing empathy skills and develop models that elucidate optimal ways for developing one's empathy. The need for developing these skills ignited fur ther interest in finding out more about how empathy is developed based on the assumption thatempatyy can be \& Naylor, 20 18; Gill, 2015)

This research sought people's viewpoint of what empathy is and why it is important personally, and in the workplace. Our findings uncovered some of the challenges that trainers and managers experience in relation to empathy and or empathy training in the workplace. We begin by presenting early findings on which this research was premised upon by way of background. We then present two of the emerging themes related to empathy burnout, and recommendations for recovery and empathy sustainability.

\section{LITERATURE REVIEW}

Empathy

Empathy has been described as sensitivity to the emotional experiences of oneself and others around them (Whiteside \& Barclay, 2016). Empathy is a social and psychological construct involving cognitive and affective factors that interact dynamically to produce compassion. According to Cherniss and Goleman (200I) empathy is an integral element of $\mathrm{El}$ and is considered one of the two foundations of social effectiveness - the other bein self-management - both of which are essential for successful relationship management. Empathy is a fundamenta component in building connections with the people in our lives, whether it be work-related or interperson relationships. Allison, Barron-Cohen, Wheelwright, Stone and Muncer (201 I) describe empathy as a tool that enables a person to be a powerful and intuitive communicator that develops an understanding of the immediate environment, and make predictions based on observing the behaviours of others and responding appropriately.

Empathy is an essential component that predisposes certain people to develop a genuine desire to help others (Martin, Rogers, Anthony \& Rowling, 2017). Empathy is a required attribute in the police force and applicants must demonstrate a significant predisposition to qualify (Charman, 2015). In addition, Charman (2015) argues that empathy does not only improve the effectiveness of a police officer, it develops a stronger appreciation of the role and a clearer perspective of unfolding events. Such perspective may enable a police officer to better care for colleagues that struggle with the complexities of the role (Martin, et al., 2017). It is not surprising that empathy is at the forefront of modern education and recruitment for police officers. As Martin, et al. (2017) states one of the main challenges facing today's police officers aside from the obvious risks, is the emotional and mental exhaustion experienced by fellow officers. Charman (2015) and Martin, et al. (2017) suggest developing empathy early on in an officer's career will equip them with knowledge and understanding of emotional fatigue that they may experience.

\section{Compassion fatigue}

Compassion fatigue or empathy burnout is described as "a syndrome of emotional exhaustion and cynicism that occurs frequently among individuals who do 'people-work' of some kind (Maslach \& Jackson, 1981, p. 99). The effort of trying to deal empathically with people all the time can lead to feeling worn out and potentially to a burnout (Johnson, 2013). Hojat (2009) notes that compassion fatigue is a real risk in professions where high levels of empathy and El are needed. Hofmeyer et al. (2016) describe compassion fatigue for nurses as "losing their nurturing ability toward patients, toward colleagues, and toward themselves" (p. 203). Symptoms of compassion fatigue include depression, anxiety despondency depersonalising patients, letharg include depression, anx iety, despondency, depersonalising patients, lethargy, lapses in concentration, low self-esteem, 2013). Compasion fatise results from dissatifotion and powerlessness to do anything about the stressors

the work environment which can be compounded by the pace of change in organisations (Radey \& Figley, 2007).

Kleiner and Wallace (2017) noted that caring professions are likely to have workers that are already emotionally and mentally burned out. As such, the medical field has been subject to much research on emotional burnout as any worker required to show empathy for extended periods of time may experience symptoms of compassion fatigue (Johnson, 2013). Hojat (2009) argues that high levels of empathy are difficult to maintain, and those working in caring professions are likely to experience a sharp decline in empathy which correlates to their length of service. Time pressure, significant caseloads, unfavourable working environments, and professional and personal relationships may be causes of decline in empathy (Slatten, Carson, Baker \& Carson, 2013). Interestingly Varca (2 employees who displayed high levels of empathy were more likely to suffer from stress and burnout.

\section{Compassion satisfaction}

In contrast, compassion satisfaction, is described by Baldschun (20/4) as the degree to which a care professional of health and human services sector professionals, finding that staff who were proactive, experienced compassion satisfaction, and were less likely to experience compassion fatigue. Proactivity relates to staff who are self-motivated, seek out opportunities to help the organisation, challenge the status quo, voice their concerns about a problem that needs to be solved or prevented, and sell their ideas enthusiastically, set action-oriented objectives and demonstrate resilience (Slatten et al., 2013).

Tierney, Seers, Reeve and Tutton (2017) noted that compassion satisfaction is moderated by the quality of relationship between the carer and their client. For example, the client shows gratitude towards their carer for 
providing compassionate assistance, thereby creating 'job satisfaction', which further encourages the carer to continue providing compassionate care, as they are 'recharged' by positive emotions. Prysmakova (2016) found that a reliance on positive feedback from a client created a level of co-dependency that may not always be fulfilled, thereby increasing the likelihood of experiencing emotional exhaustion and compassion fatigue. Tierney et al. (2017) stated, "Without a degree of reciprocity; without the carer's needs being recognised, and without finding meaning in the interaction, one-way compassion is likely to lead to burnout" (p. 10). Managers must therefore take proactive measures to inform and protect their workers to reduce the risk of compassion fatigue (Somog) Buchko \& Buchko, 20/3). A proactive measure such as a top-down commitment to fostering an encouragin and supportive environment where the delivery of compassionate care is of paramount importance, mitigates the effects of empathy 'drain' (Tierney et al., 2017). Additionally, support measures or benefits such as employee assistance programmes, are essential for providing the tools and resources to manage work-related stress (Kleine \& Wallace, 2017)

\section{Organisational structures and empathy}

In contrast, Prysmakova (2016) noted that centralisation at an organisational level further complicated worker experiences, as control and decision-making power is reduced, and workers may feel micro-managed by an overarching policy or procedure. The impact of centralisation on workers is that they do not have discretion to deal with individual situations, but are forced to use a blanket approach that is oftentimes inadequate to meet the clients' needs.

Workers are likely to experience compassion fatigue if they believe the organisation does not care about them as an individual (Tierney et al., 2017). For workers to address their own needs, Slatten et al. (2013) described the use of supportive group interactions to increase compassion satisfaction and self-awareness of their emotions and cognitive function. Proactive workers thrive in cohesive groups as they are interpersonally fulfilled through their compassionate work with patients and colleagues. Furthermore, interactions in supportive groups allow workers to show concern, empathy and interest in their colleagues' welfare, thereby positively affecting their compassion

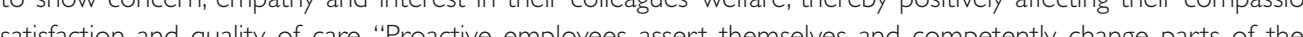
wark envist of their work be unstain

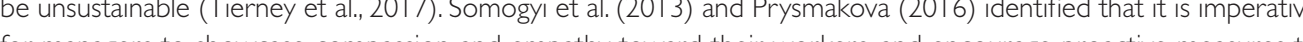
mintain compassion satisfaction and reduce the risk of compassion fatigue.

\section{RESEARCH METHOD}

Semi-structured interviews were conducted with a pilot group of five empathy trainers and five managers of organisations where empathy was signalled as a key skill. These spanned: nursing, police, aged care, midwifery disability sector, museum and church-based organisations. The purpose of the inquiry was to mine participants' perspectives of empathy in the workplace so as to increase our understanding of empathy, highlight empathy issues and identify components that contribute to developing and/or regenerating worker empathy

Semi-structured interviews provide flexibility to explore participants' perspectives (Dey, 1996). The interviews took 30-45 minutes each, were audio recorded and transcribed. Findings were then analysed and organised into themes. Corbin and Strauss (2008) emphasise the interactive nature of this analysis process. As this research was carrie out as a pilot study and the sample size was small, this can be seen as a limitation of this research. Nevertheless, the findings highlighted useful themes and strategies for reducing compassion fatigue and sustaining empathy

\section{DISCUSSION:THEORETICALAND PRACTITIONER IMPLICATIONS}

Compassion fatigue in caring profession workplaces was embedded, which has implications for health and safety in organisations, and the responsibility this places on managers to ensure the health of their workers. The discussion follows two threads: compassion fatigue and; identifying strategies to combat empathy burnout.

\section{Compassion fatigue}

One of the issues contributing to compassion fatigue is establishing boundaries between work and 'rest from work (some might call it worklife balance); or perhaps better defined as work-engaged, and work-unengaged. Employees who are 24-hour contactable never have an opportunity to be fully unengaged, which means psychological and emotional demands are being made on them all of the time; wating for the phone to ring is work, and then dealing with the issues that people raise when they phone, as these comments describe: I've always given people my cell phone number so they can contact me, so
I'd spend a lot of time at home, and in the weekends talking to the people
I am dealing with, and I think that I did that for such a long time. It's very
consuming...I think it takes a toll on the individuals and me. I got to a point
where I felt like l'd hit a wall, and I couldn't - I felt that I lacked empathy at
home, I could give it at work, but I couldn't give it at home.

You're giving, giving, giving so much in your role, that you get tapped out, and it takes its toll on you.

I'm quite clear on my boundaries.

Another participant explained that setting boundaries is not always that easy in a support or care environment:

We have all of this in policies, such as professional boundaries. So we try to

say. "This person is your staff not your friend" The problem with that is a lot of

the people we support don't have any friends. They don't have friends outside

of the staffing maybe not even their family. So for them, we may be the only

people coming in and we're sarin "W''re not rour friends" So it seens kind of

weird, but it's one of the [issues] of professional boundaries.

Similarly, workers in caring industries commented that their colleagues/clients/customers were embedded in their work, that is, they were the focus of their work, and comprised a very important part of the work they do. Research carried out by Hojat et al. (2009) showed that although empathy levels remained constant through the first two years of their subjects' medical training, by the third year their empathy levels had declined significantly. The reasons for this decline were varied and complex, and included time pressure, a lack of role models, a high volume of materials to learn, and patient and environmental factors. Patients' or clients' situations and needs can be demanding, and therefore, can be quite draining on the carer's reserves. Thus, care workers needed to have strategies for safeguarding themselves from getting too involved emotionally, and giving too much.

When you do become emotionally involved, you build defences to protec yourself:And that stops empathy from running its proper course.

This participant points out that they need to somewhat withdraw giving empathy for self-preservation. Participants voiced that having a name for it - compassion fatigue - assigned it value and called it for what it was, thereby helping them see that they were not weak, failing or performing poorly.

It was good to be able to call it something, and that I wasn't just being o grumpy mum. 
Having an appreciation that the expenditure of empathy in their work had consequences in other parts of their life, was a revelation for some:

It [brought] a realisation that I needed to have a break from that [work] environment.

Care workers identified the psychological strategy of differentiating between work engaged and work-unengaged such as creating express delineation between work and home life.

I have to protect myself emotionally too. The biggest thing I do to protect me, not wearing my uniform at home. It's like a switch. I can relax and detach, an that's how I protect myself.

Another tactic that participants used was to deliberately disengage from the negative affect of the situation by mindfully contemplating potential good that might emerge from the difficult or demanding situation:

In terrible things, we see benefits. It does come with working in our world a little bit, and sometimes it helps keep people sane. It's a coping mechanism in a way.

Krasner et al. (2009) note that "physician burnout has been linked to poorer quality of care, including patien dissatisfaction, increased medical errors, and lawsuits and decreased ability to express empathy" (p. 1284), whil West et al. (2006) reported that "increased burnout in all domains and reduced empathy were associated with depersonalisation, emotional exhaustion, and lower personal accomplishment " (p. I 07I).These are all good reason for the development of strategies for workers to sustain empathy levels and avoid experiencing burnout.

\section{Identifying practical strategies}

Participants used several actionable strategies for maintaining their empathy, which we have collated. Based on these findings, three strategies emerged, which are:

Increasing colleague support

2. Creating opportunities to share experiences (formal and informal)

3. Increasing quality of communication at all levels of the organisation

Each of these strategies is discussed in turn.

\section{Increasing colleague support}

Increasing opportunities to collaborate conceptualises the adage, 'a burden shared - a burden halved', as these comments convey

People are encouraged to collaborate, we've got open planned offices,

encouraging people to talk about cases.

We try to provide a healthy work-life balance thing, we have team building

Ways. we have stuff like that We try to promote some sort of social interaction amongst the staff

Schwerman and Stellmacher (2012) suggested improving the support of colleagues and increasing the quality of communication at all levels of an organisation enables workers to share their experiences with others in similar work environments. Thompson (2013) found that providing workers with an opportunity to share their stories with others - particularly those in caring professions, reminds them of why they entered the profession, and gives them renewed sense of value, compassion and empathy to carry on in their work

\section{Creating opportunities to share experiences (formal and informal)}

Creating a work environment that expressly gives opportunity for workers to download the human tragedy of their clients, customers and co-workers, values the workers' contribution and the stories of customers, clients and staff. Sharing experiences is very helpful and supportive for care workers who continually offer empathy in their work situations, as it provides opportunity to unload the emotional baggage they have carried for the people who needed it, to gain 'perspective', and to support each other as these comments explains:

We tend to talk a lot to each other.A lot of the really horrible stuff we deal with, does get dealt with by black humour.

We promote the discussion of cases. And we promote transparency of work So if someone has their work looked over, and say "Hey what are you doing" we encourage it. And that helps maintain that kind of sense of normality of understanding of what is right of other people, by having others look at your practices.

Tierney et al. (2017) noted that reciprocity was needed to counter empathy burnout in that carers need to be consistently 'filling their tank' to create a reservoir from which they give out of. For workers to address their own needs, Slatten et al. (2013) described the use of supportive group interactions where workers could share their work stories within their specific service/caring workload (as opposed to on top of). Cohesive groups provide a platform to talk freely; and have high trust, which is an excellent environment in which to have vulnerable conversations. Gill Ramsey and Leberman (2015) identifed that trust is a "vita aspect of a safe environment where [people] could talk freely and disclose information that was linked to feelings of vulterability" (2 268) Furthermore interactions in supportive groups allow workers to s interactions in supportive groups allow workers to show concern, empathy and interest in their colleagues' welfare
while experiencing support personally.

\section{Increasing quality of communication at all levels of the organisation}

Many of the participants commented that their organisation was committed to encouraging staff to undertake supervision, to talk about the situations they are expending empathy.

I guess supervision has always been a good thing, and I have asked for additional supervision in the past

every staff member here has supervision.

Finding a trusted person outside of the workplace was also identified as a useful strategy for preventing empathy fatigue:

I talk to my husband a lot. He's really good to talk to. Even just talking, because nothing else really changes it.

Participants noted the value of both formal and informal communication in the workplace, for example:

Training and meetings, but l'd also talk to [my staff] one to one as a team 


\section{Just talk to them about it}

I certainly think having a more diverse workplace [different caring departments]

has probably made us more empathetic.

However, different organisational structures and staffing might pose some challenges to communication. One participant commented on this

And you might not even see the other staff very often. Like you'd be working on shifts, one to one, so you wouldn't even see a hand over where you'd leave notes around for other staff.

Additionally, workers need to take time to rest; physically, emotionally and mentally, to sustain their levels of empathy for others. Ekeland, Ornes, -inset and Pedersen (2014) conducted research with third-year medical students, noting that several studies have shown a decline in empathy amongst medical students in their third year. One of the reasons given by the students for their declining empathy was that the importance of biomedical learning took precedence over their ability to manage the emotional aspects of their relationship with their patients. Although students received tuition in communication, behavioural science, and empathy, time constraints meant that the focus was on taking the patient's medical condition This seems unfortunate as according to Simpson et al ( 199 |) "effective communication between doctor and patient is a central clinical function that cannot be delegated" (D.1385) and the quality of clinical communication is beneficial to patient outcomes The authors also believe that the teaching of active listening and empthy shills is proven to be of unquestionable benefit to the doctor patient relationship. the frontline, so that offering enpathy

on a long term basis is realistic and achievable.

\section{CONCLUSION}

Compassion fatigue, which describes the expenditure on a care worker's empathy to the point where it creates a rea risk to health of the care professionals, is costing organisations, both financially and the human cost of empathically burnt-out workers. The ever-increasing pace of change in organisations provokes responsible leaders and managers to explore proactive ways to educate and improve the health and welfare of their workers, and reduce the risk of compassion fatigue before it occurs, as well as tackle its after-effects in current workers. Developing self-awarenes of compassion fatigue enables the worker and their colleagues, to identify signs and symptoms in themselves and others, and so to seek help before these symptoms escalate to the point of 'break-down'. Creating supportive networks and opportunity to rest allows workers in caring industries to recharge, and re-generate their empath reserves. Increasing the quality of communications in and across all levels of the organisation, provides impetus and opportunity to give and receive understanding, support and empathy in industries that endure continuous change and work on the coalface of society's human challenges. Empathy training in the workplace would also hold much benefit by alerting care workers to the warning signs of empathy depletion and offer new insights and understanding for balancing empathy reserves and empathic expenditure.
Marjolein Schaddelee(Marje) is an Academic Learning Advisor at Otago Polytechnic. Her research interests are in the areas of organisational learning and organisational behaviour.These areas of interest have paved the way for people in the workplace demonstrate empathy and authenticity.

Samuel Turner is a recent Human Resources Management graduate working in the People and Culture team at Otago Polytechnic (OP). Sam's research focus is in Emotional Intelligence and Contemporary HR, specifically areas committee, and remaining connected with business degree students.

Dr Lesley Gill is a Principal Lecturer at Otago Polytechnic, teaching Leadership, Human resource management and Strategic Management. Her PhD focused on Emotional Intelligence training design. Lesley runs workshops in search in qualityinternational and national peer-reviewed journals publications and conferences, and co-authore Organisations \& Management textbook.

\section{REFERENCE LIST} Allison, C., Baron-Cohen, S. Wheelwright, S. .., Stone, M. H. \& Muncer, S. I. (201 I) Psychometric analysis of the Empathy Quotient

Baldschun, A. (2014) The six dimensions of child welfare employees' occupational well-being. Nordic Journal of Working Life Studies,

Charman, S. (2015) Crossing cultural boundaries. International Journal of Emergency Services, 4(2), $158-176$

Cherniss, C.\& Goleman, D. (2001) The emotionally intelligent workplace: How to select for, measure, and improve emotional intelligence

Corbin, J. \& Strauss, A. (2008). Basics and qualitative research. Thousand Oak, CA: Sage.

Dey, I. (1996). Qualitative Data Analysis:A user-friendly guide for social scientist. London, England: Routledge.

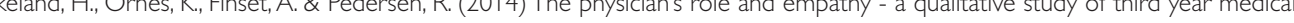
students. BMC Medical Education, I4(I), 165-173.

Gill, L., Schaddelee, M., Ramsey, P., Turner, S. \& Naylor, T. (2018) When empathy works. Towards finding effective ways of sustaining empathy flow. Asia-Pacific Management and Business Application, 6(3), II5-136.

Gill, L.J. (2015) Exploring trainer perspectives of emotional intelligence training design. PhD thesis Massey University

Gill, L.J., Ramsey, P. L. \& Leberman, S., ( 2015) From chaos to transformation safely. The Emotional Intelligence Learning Environment Model. Jurnal of Organisational Transformation and Social Change, I2(3), 257-286.

Hofmeyer, A., Toffoli, L.,Vernon, R., Taylor, R., Fontaine, D., Klopper, H. C. \& Siedine, K. C. (2016) Teaching the practice of compassion to nursing students within an online learning environment: A qualitative study protocol. Contemporary Issues in Education

Hojat, M. (2009) Ten approaches for enhancing empathy in health and human services cultures. Journal of Health and Human Services

Hojat, M. Vergare, M., Maxwell, K., Brainard, G., Herrine, S., Isenberg, G., Veloski, J. \& S. Gonnella, J. (2009) The devil is in the third year: A longitudinal study of erosion of empathy in medical school. Academic Medicine: Journal of the Association of American

Johnson. D. (2013) Empathy can be exhausting. ISHN, 47(9). 10.

Kleiner, S. \& Wallace, J. E. (2017) Oncologist burnout and compassion fatigue: Investigating time pressu

Krasner, M. S., Epstein, R. M., Beckman, H., Suchman, A. L., Chapman, B., Mooney, C. J. \& Quill, T. E. (2009) Association of an educational program in mindful communication with burnout, empathy, and attitudes among primary care physicians. IAMA, 302(12). $1284-1293$ 
Marques, J. (2015). The changed leadership landscape: What matters today. The Journal of Management Development, 34(I0), I3 I01322.

Martin, H. C., Rogers, C., Anthony, J. S. \& Rowling, M. (2017) Serving from the top: Police leadership for the twenty-first century. International Journal of Emergency Services, 6(6), 209-219.

Maslach, C. \& Jackson, S. (198I) The measurement of expereinced burnout. Journal of Organisational Behaviour, 2(2), 99- I I 3.

Mehrabin, A. \& Epstein, N. (1972) A measure of emotional sympathy. Journal of Personality 40(4), 525-543.

Prysmakova, P. (2016) From compliance to commitment. International Journal of Manpower, 37(5), 878-899.

Radey, M. \& Figley, C. R. (2007) The social psychology of compassion. Clinical Social Work Journal, 35( I), 207-2I4.

Salam, M. (2019, March 22). Jacinda Adern is leading by following no one. The New York Times. Retrieved from https://wmw.nytimes. com/2019/03/22/world/australia/jacinda-ardern-new-zealand-leader.html.

Schwerman, N. \& Stellmacher, J. (2012) A holistic approach to supporting staff in a paediatric hospital setting. Workplace Health \& Safety, 60(9), 385-390.

Simpson, M., Buckman, R., Stewart, M., Maguire, P., Lipkin, M., Novack, D. \& Till, J. ( 99 I) Doctor-patient communication:The Toronto consensus statement. BMJ: British Medical Journal, 303(68I4), I 385- 1387.

Slatten, L., Carson, K. \& Carson, P. (20I I) Compassion fatigue and burnout: what managers should know. The Health Care Manager, 30(4), 325-333.

Slatten, L. A., Carson, K. D., Baker, D. S. \& Carson, P. (20I3) An expansion of the beneficial outcomes associated with the proactive employee. Journal of Behavioural and Applied Management, 14(3), I62- 172.

Somogyi, R. L., Buchko, A. A. \& Buchko, K. J. (2013) Managing with empathy: Can you feel what I feel? Journal of Organizational Psychology, I 3(1), 32-42.

Thompson, A. (2013) How Schwartz rounds can be used to combat compassion fatigue. Nursing Management, 20(4), 16-20.

Tierney, S., Seers, K., Reeve, J. \& Tutton, L. (2017) Appraising the situation: A framework for understanding compassionate care. Journal of Compassionate Healthcare, 4(I), I-8.

Varca, P. E. (2009) Emotional empathy and front line employees: Does it make sense to care about the customer? The Journal of Services Marketing, 23(1), 5 I-56.

West, C. P., Huschka, M. M., Novotny, P. J., Sloan, J. A., Kolars, J. C., Habermann, T. M. \& Shanafelt, T. D. (2006) Association of perceived medical errors with resident distress and empathy: a prospective longitudinal study. JAMA, 296(9), I07 I- 1078.

Whiteside, D. B. \& Barclay, L. J. (2016) The face of fairness: Self-awareness as a means to promote fairness among managers with low empathy. Journal of Business Ethics, 137(4), 721-730.

Williams, B., Boyle, M. \& Howard, S. (2016) Empathy levels in undergraduate paramedic students: A three-year longitudinal study. Nurse Education in Practice, $16(1), 86-90$. 